\title{
Juan Egaña, Precursor de la Integración Americana
}

\section{por Raúl Silva Castro, de la Academia Chilena}

\author{
Trabajo en conmemoración del bicentenario
}

de don Juan Egaña

Don Juan. Egaña, el protagonista de las aventuras ideológicas que en seguida se narrarán, nació en Lima, Perú, el 31 de octubre de 1768 , pero hijo de chileno se le tiene tradicionalmente por ciudadano de Chile, en virtud de la esencia de textos constitucionales concordantes, que se han sucedido en diferentes fechas. Por lo demás, para llamarle chileno y no peruano milita una muy especial circunstancia: Egaña hizo viaje en 1789 a la patria de su padre y desde entonces no regresó nunca más al Perú. En Chile, donde contrajo matrimonio, nacieron sus hijos y, en fin, dejó de existir el dia 29 de abril de 1836 . Tal como otros americanos ilustres, nacidos en el periodo de la dominación española, no parece haberse sentido en modo alguno embarazado para intervenir en la vida politica de Chile asi como nadie le hizo pesar el hecho de haber nacido en Lima como impedimento para opinar, aconsejar, actuar y dirigir, en una nación que no era la de su nacimiento, si bien había sido la cuna de su padre y de muchos de sus otros antepasados.

En la historia de las ideas de la América de lengua española parece llegada la hora de reivindicar un puesto para Egaña, asi por cuanto hizo y proyectó para Chile como por el pertinaz estudio de una forma de organización supranacional que habria debido realizar una especie de confederación anfictiónica de estados en la cual ninguno de éstos perdiera su autonomia sino en el grado necesario para llevar a sus últimas consecuencias la articulación supranacional. Y, como se verá en seguida, Egaña mantuvo en estudio la idea a lo largo de años, la revistió de nuevos contornos y la adaptó no pocas veces a las necesidades emergentes, en consonancia con las noticias que recibia, en su observatorio santiaguino, acerca del comportamiento de las naciones a mericanas.

Según el historiador de la diplomacia chilena en el periodo inicial de su existencia ${ }^{1}$, el tema de las relaciones entre estados fue formulado antes que nadie por Juan Martinez de Rozas en la oración inaugural del Congreso de 1811. Sin discrepar de tal dictamen, se nos permitirá recordar que Egaña habia señalado ya en su Plan de Gobierno de agosto de 1810 una proposición donde puede ubicarse también la fuente de aquellas relaciones. En este

\footnotetext{
${ }^{1}$ Don Ricardo Montaner Bello, en Historia Diplumática de In Independencin de Chile, Santiago, 1941, p. 10-11
} 
documento aparece un párrafo especial titulado Politica Exterior, por el cual se récomienda al Conde de la Conquista, su destinatario, escribir inmediatamente "a los demás gobiernos de América (aunque sea del sur) para que estén prontos los diputados de las Cortes". Es, tal vez, la parte más débil del plan, aparentemente menos meditada y redactada con cierta prisa; pero, en todo caso, el pensamiento de entablar relaciones con "los demás gobiernos de América" basta a nuestro objeto. Sobre el verdadero carácter de las insinuaciones hechas al Conde de la Conquista no se engañaron los realistas, que seguian muy de cerca las actividades de los patriotas. El más descollante de ellos, fray Melchor Martinez, juzga en su Memoria Histórica con Ios siguientes términos el documento referido:

"Desde este tiempo ya se quitaron la máscara los proyectistas y directores del nuevo sistema, y uno de loș principales papeles de esta especie, D. Juan Egaña, obsequió al nuevo Presidente presentándele una memoria o plan del gobierno interior y exterior que tenia meditado y prevenido de antemano para este caso, en que propone las reformas que deben hacerse $y$ detalla las medidas y leyes que deben regir en adelante lisonjeando al gobierno con tan altas facultades que apenas pueden competer a un soberano monarca. Desde sus primero párrafos aconseja se declare el comercio libre, se estipulen tratados con naciones extranjeras, se impongan tributos, se establezcan leyes, se instituya un Congreso general entre las provincias americanas, y en resumen conoce al Reino de Chile como a una potencia independiente y soberana." (Obra cit., p. 71).

Este resumen es fidelisimo, aun cuando el autor lo haga con todas las reservas debidas a la repugnancia que sin duda le inspiraba la sugestión de Egaña, dirigida, como él bien dice, a producir en el ánimo del Conde de la Conquista la persuasión de que el Reino de Chile debia obrar en lo futuro como "potencia independiente y soberana".

El establecimiento die relaciones diplomáticas, en suma, habia sido insinuado ya al Conde de la Conquista, varios meses antes de la instalación del Primer Congreso Nacional, y era natural que asi fuese. Egaña se coloca alli en la necesidad de que estos paises, siquiera fuesen sólo los de la porción austral del continente americano, como hace explicita mención, se consulten a hin de alcanzar una linea uniforme de conducta para cuando llegue el caso de que sus diputados entren a componer la junta central de gobierno, que reunida en el territorio español aparecia, a las alturas de agosto de 1810 , sujeta a multitud de imprevistas y desagradables contingencias. Precisa, más aún, que en esa reunión preliminar las nuevas naciones deben ponerse de acuerdo en lo que toca "al orden de unión y régimen exterior que debe guardarse entre las provincias de América, hasta las Cortes generales", labores todas que sólo se habrian podido confiar a representantes debidamente autorizados, esto es, a diplomáticos.

Por lo demás, las cosas se ordenaron de modo que antes de expresar 
Martinez de Rozas las palabras recordadas, ya hubiese relaciones diplomáticas con una de las provincias americanas que habian precedido a Chile en la organización de gobierno. Se trata de Buenos Aires, cabeza de lo que iba a ser más tarde la República Argentina. Desde octubre de 1810, por lo menos, existen documentos que revelan la existensia de activas relaciones entre los gobiernos santiaguino y bonaerense ${ }^{2}$; y no es menos significativo que la junta de gobierno haya creido también posible dirigirse a los embajadores de España y de Grañ Bretaña en Rio de Janeiro (2 de octubre). Pero la junta iba a dar un paso más decisivo: en la nota de 26 de noviembre de 1810 decia a la de Buenos Aires lo siguiente:

"Convencidos estos pueblos del interés que reciprocamente nos obliga a la más estrecha unión con las valerosas provincias del Rio de la Plata, manifiesta su satisfacción en la general alegria con que ven consolidadas todas sus relaciones, en la sincera amistad y conformidad de ambos gobiernos. Esta junta conoce que la base de nuestra seguridad exterior y aun interior, consiste esencialmente en la unión de la América, y por lo mismo desea que en consecuencia de los principios de V. E. proponga a los demás gobiernos (siquiera en la América del Sur) un plan o congreso para establecer la defensa general de todos sus puntos y aún refrenar las arbitrariedades y ambiciosas disensiones que promueven los mandatarios (se refiere a las autoridades que en algunas regiones gobernaban todavia en nombre del Rey de España, como puede comprobarse por otros documentos de la misma pluma), y cuando algunas circunstancias acaso no hagan asequible este pensamiento en el dia, por lo menos lo tendrá V. E. presente para la primera oportunidad, que se divisa muy de cerca".

El mismo pensamiento se formula en la nota dirigida por la junta de gobierno al Marqués de Medina en Io de diciembre de 1810 :

.... La junta provisional gubernativa... dejó al cargo del gobierno la provisión de los demás empleados subalternos, todo provisionalmente hasta restaurarse la monarquia o verificarse las cortes en concurso de toda la América y España".

La doctrina de Egaña acerca de la posible convocación de un congreso general de diputados americanos o, como dijo más adelante, de una Dieta, se concretó rápidamente. El Plan de Gobierno ya aludido fué redactado en agosto de 1810 y es anterior, en todo caso, a la convocación del Cabildo Abierto de 18 de setiembre. Poco después, y tal vez antes de 1811 , Egaña redactaba el Proyecto de una reunión general de las colonias españolas, donde se lee el siguiente exordio:

"En el dia que la Excma. Junta trata de los medios de seguridad y defensa del Reino, me parece una obligación debida a mi patria y a mi Rey tocar

\footnotetext{
2 Algunos de los documentos emitidos por la junta de gobierno formada en setiembre de $1810, x$ publicaron en el apéndice documental de El Coronel don Tomás de Figueroa, por Benjamin Vicuña Mackenna, Santiago, 1864, p. 3 y sigs. de la segunda numeración.
} 
un punto que conciliando nuestra seguridad territorial asegure también la integridad de toda la América, que es el más precioso y tal vez por desgracia el único resto con que podemos contar. Segura toda la América, !o estaremos nosotros a menos costo y con más descanso para ocuparnos en la felicidad interior de Chile, y tendremos con qué auxiliar a la metrópoli. Para este objeto el único medio y el que se presenta a primera vista es un plan de defensa general.de toda la América del Sur, hasta.que pueda ser llamada y tenga tiempo para concurrir la del Norte"”.

Es trascendental la innovación registrada ahora. Por el documento anterior pudo verse que Egaña hizo la reserva de que debian reunirse delegados de los Estados del Sur, pues la premura del tiempo impedia hacer invitaciones más amplias. Ahora Egaña quiere que en la reunión figuren también delegados de la América del Norte, entendiendo tal vez, en sentido geográfico restricto, sólo a México, o tal vez, con mayor amplitud politica, también a los Estados Unidos. El plan se labra ante el peligro de que Europa intervenga en los asuntos americanos, para luchar por el restablecimiento de la monarquia y de los imperios coloniales, peligro sin duda parejo para los Estados Unidos, que ya habian consolidado su independencia, como para las naciones de lengua española, en donde la lucha por la emancipación estaba apenas comenzando. Entonces el autor agregaba:

Nosotros sólo tenemos un remedio para todas estas desgracias, pero un remedio universal, capaz de destruir todos los planes que la Europa haya formado en mil siglos; éste es la reunión de toda la América y el prestarse una defensa mutua para todos sus puntos organizando un plan general de las obligaciones y contribuciones que debe hacer cada gobierno en armas, hombres y dinero para el caso del menor ataque o seducción de la Europa.

Imagina el tratadista un congreso general de representantes de los paises americanos, nombrados "sin tropezar en la legitimidad de su gobierno", congreso al que competeria formar "el acta provisoria de integridad y defensa general de América". Tendria asimismo aquel organismo supranacional la tarea de servir de "mediador y conciliador provisorio para las disensiones intestinas que ocurran entre las opiniones de unos gobiernos de América con otros, de suerte que no procedan a hostilidades sin consultar esta comisión". Puede verse cómo en algunas de estas articulaciones, Egaña avanza notablemente hasta coincidir casi con los planes y programas de instituciones como las que actualmente existen, esto es, Naciones Unidas y Organización de Estados Americanos. Para dar mayor relieve a la urgencia de sus propuestas, Egaña agregaba todavia:

"¿Qué podrá objetarse contra esta resolución? ¿Se dirá que aun no es tiempo, que no hay necesidad? Pero véase bloqueado a Buenos Aires y cómo

\footnotetext{
${ }^{3}$ Las expresiones copiadas en el texta proceden del Proyecto que con el titulo de Plan de defensa general de toda la America se ha publicado en Escrilos inédilos y dispersos de Egaña, Santiago, 1949. p. $43-52$.
} 
la Inglaterra nada menos trata que de calmar estas disensiones, $y$ antes se ha reconocido el bloqueo con todas sus formalidades como entre dos potencias soberanas teniendo a la vista en el Brasil (según se nos avisa) nueve buques de guerra, y véase a la corte del Brasil con diputados en Montevideo, a quien se dice (aunque no debe creerse) que han ofrecido esta plaza".

En seguida indicaba otros pormenores relativos al Perú, a Quito, etc., como prueba de la necesidad imperiosa de formas de conciliación para evitar las guerras entre vecinos. Tendiendo la mirada hacia el futuro decia también:

"Lo cierto es... que en el dia que se practique y llegue a noticia de la Europa nuestro proyecto de defensa, sólo con él bastará para asegurarnos de invasiones y seducciones. Ninguno se atreverá a despachar una armada sabiendo la precaución en que vivimos..."

Respecto de la sede de tal reunión, es oportuno señalar que Egaña, anticipáncose a la sugerencia de Bolivar, formulada años después, dió ya el nombre de Panamá, cual puede verse en sus propias palabras:

"Pero ¿cuál será el punto donde deban reunirse estos diputados? Si se tratase en el dia de ambas Américas, ya se ve que el estrechio de Panamá o alguna ciudad inmediata. Pero si atendida la urgencia queremos juntas la América del Sur hasta que pueda llamarse la del Norte, Guayaquil o sus inmediaciones parece más adaptable".

Las expresiones finales de este singular documento, aplicadas sólo a Chile $y$ a sus relaciones internacionales directas, son dignas de ser repetidas una vez más:"

"Chile, por las barreras que le ha puesto la naturaleza, debe temer poco los insultos de sus vecinos, y sabe que ningún pais de toda la América es proporcionalmente tan poblado y de gente tan robusta y valerosa para defender sus playas. Tiene recursos para subsistir interceptado de todos los paises del universo, y con una buená administración tendria riquezas que abundasen con exceso para prepararse con todo género de armamentos, con que este pensamiento debe principalmente calificarse por un conato de amor a sus hermanos"4.

Poco más adelante, invitado Egaña por el Congreso Nacional a redactar un proyecto de Constitución Politica del nuevo estado, produce la primera forma de las que se le deben, la de 1811 , donde se da maña para introducir algunos articulos que conduzcan a Chile a dar los pasos iniciales en la formación de una entidad supranacional. Si el proyecto hubiera sido entonces aprobado, asi habrian discurrido las cosas. Baste para entenderlo repasar los siguientes articulos:

${ }^{4}$ El papel sobre ta Diela soberana de Sud América fue recogido en los Eseritos Inéditos y. Dispersos, Santiago, 1949,
p. 5 2-8. 
Art. II

"El pueblo de Chile retiene en si el derecho y ejercicio de todas las relaciones exteriores, hasta que formándose un Congreso general de la nación, o la mayor parte de ella, o a lo menos de la América del Sud (si no es posible el de la nación), se establezca el sistema general de unión y mutua seguridad, en cuyo caso transmite al Congreso todos los derechos que se reserva en este articulo".

Art. IV

"Chile forma una nación con los pueblos españoles que se reúnan o declaren solemnemente querer reunirse al Congreso general constituido de un modo igual y libre".

Hemos dejado aparte, por su trascendencia, las declaraciones que sobre política internacional contiene en su preámbulo el proyecto de Constitución que en 1811 redactó Egaña. En el sentir del autor, la Constitución debia ser precedida de una Declaración de los Derechos del pueblo de Chile, y el proyecto compuesto para esta Declaración se lee antes de la Constitución propiamente tal, en la publicación hecha en 1813 . Nótese bien que Egaña entendia legislar para "un pueblo que trata de dirigirse a si mismo", asi en lo interno como en sus rèlaciones internacionales, y cómo para hacer posible la "soberanía aislada" le pareció conveniente asegurar, al mismo tiempo, la defenza conjunta de las diversas provincias americanas ante los peligros que podrian eventualmente amenazarlas también en conjunto. Por eso pasa a examinar esos peligros en los siguientes articulos de la Declaración. "... Es casi imposible - dice - que la América pueda consolidar perfectamente sus sistemas sin ponerse de acuerdo con la Europa, o con alguna parte principal de ella". I a consecuencia era obvia:

"Que el dia que la América, reunida en un Congreso, ya sea de la $\mathrm{Na}$ ción; ya de sus dos continentes, o ya del Sur, hable al resto de la tierra, su voz se hará respetable y sus resoluciones dificilmente se contradecirán".

Creía además el autor que los viriculos "de sángre, idioma, relaciones, leyes, costumbres y religión" facilitarian la tarea, pero que "sobre todo, tenemos una necesidad urgentisima de verificarlo, que nos ha de inducir irresistiblemente a ello". No llega a imaginar que España, sometida a la sazón a serias combustiones politicas, fuera quien podria impedir el paso que Egaña pedia a las provincias del Nuevo Mundo; ni que los virreyes de Lima y de México, por su parte, se atrevieran a oponerse: 
"Su poder es precario, abusivo —asentaba- y sin representación legal; cada novedad que sobrevenga al gobierno español ha de debilitar más la influencia de los virreyes y el partido que tenga là España en América".

Le parecia, en fin, que cuando los americanos decidieran reunirse en el Congreso propuesto, "es muy dificil que los virreyes tengan la impudencia de negarse a su formación, y casi imposible que los pueblos toleren tal iniquidad".

Con estas palabras despectivas para los virreyes, Egaña parecia responder a la parte final del oficio que el de Lima envió a la junta de gobierno con fecha 12 de octubre de 18 12. El virrey estaba, a lo que se colige, muy bien informado de los sucesos de Chile, pues dijo nada menos que ésto:

"Admitan vv. la Constitución nacional de que acompaño un ejemplar y que con inexplicable placer y júbilo acaban de jurar los pueblos españoles, y entre ellos esta inmortal e insigne capital que tengo el honor de mandar; condenen $\mathrm{vv}$. a las llamas y a un eterno olvido la que están para adoptar $y$. tienen puesta en examen, como un eterno baldón de ignominia y el más feo borrón de la fidelidad del Reino; y cuenten $v \mathrm{v}$. con cuantos auxilios pueda y deba prestar..."

Cual pudo verse más arriba, las primeras relaciones propiamente diplomáticas de Chile fueron dirigidas a mantener perfecta coordinación de inspiraciones con Buenos Aires, si no en vano el movimiento de 25 de mayo alentó a los patriotas de Chile a asumir la responsabilidad asumida en el curso de ese año, hasta desembocar en el Cabildo Abierto de 18 de setiembre de 1810 . Las relaciones fueron por algún tiempo unilaterales, porque mientras Buenos Aires tenia acreditado un representante en Chile, don Antonio Alvarez Jonte, no habia un chileno que hiciera sus veces en la capital del Plata. El 9 de octubre de 181 I el Congreso aprobó crear ese cargo, para que un funcionario con sede en Buenos Aires informara a la junta de gobierno $y$ al Congreso de las noticias que pudieran interesarles, y en la misma sesión se procedió a nombrarlo en la persona de Francisco Antonio Pinto. Contaba veintiseis años de edad, era abogado de profesión y habia pasado buena parte de su entonces corta vida fuera de Chile, ya que se educó en Lima. Pinto se trasladó a Buenos Aires y estuvo alli hasta que, en junio de 1813 , la junta de gobierno compuesta por Francisco. Antorio Pérez, José Miguel Infante y Agustin de Eyzaguirre resolvió ampliar su misión. En el documento por el cual se extendió la designación, se decia que el enviado pasaria "a la Corte de S. M. el Rey del Reino Unido de la Gran Bretaña e Irlanda y a las demás de Europa y América que no tengan miras contrarias a la tranquilidad, seguridad y derechos del pueblo chileno".

Cuando llegó el momento de dar instrucciones al representante diplomático, fué a la pluma de Egaña a la cual se cometió el encargo. Egaña dividió su tratado en tres partes, la primera propiamente política, económica la segunda y sobre asuntos eclesiásticos la tercera. Finalmente, a ello 
añadió larga nómina de los aparatos e instrumentos y materiales necesarios para montar un completo laboratorio de quimica, que le parecia con razón indispensable en un pais minero. En la primera parte hallaremos manifestado una vez más el pensamiento del autor acerca de la organización que debia asumir el gobierno y de las relaciones que éste se hallaba dispuesto a mantener con los demás pueblos del mundo.

Comienzan en esta parte las instrucciones por señalar cómo el representante chileno debia tratar no sólo con el gabinete de Gran Bretaña sino también con "las demás Cortes con quienes puedan versarse los intercses de este pais de läAmérica Española". En lo que se refiere a aquella nación, se dice en las instrucciones que existe aqui el recelo de que Inglaterra "piense en algún sistema colonial y de monopolio respecto de las Américas", y sobre España se manifiesta sobre todo el peligro de que ella intente declarar algunos derechos por via de sucesión o protección a otros principes extranjeros "cọn cuyas resoluciones se turbe la paz de América". En casos tales, dicèn textualmente las instrucciones, "es preciso estar a la mira, asi de penetrar estos designios como de cortarlos".

Egaña formula además en este documento la teoria de la libertad de comercio en Chile para que a sus puertos lleguen barcos de todas las naciones. Sugiere "también tener libre la navegación del Asia para expender sus frutos y procūrarse manufacturas de algodón de que es probable que siempre carezca". En otra parte de las instrucciones, señala la llamada más adelante "insularidad" de Chile, al cual nombra "el pais más defendido de América"; insularidad que nace de los caracteres fisicos del territorio, definidos de una pincelada, y que se extiende hacia los contornos politicos que haya de alcanzar la acción del gobierno chileno dentro del continente.

"En una palabra - concluye Egaña-, la armonia politica de Chile debe ser la interior de los suizos en Europa, sin perjuicio de que en la actual convulsión y peligros de América, concurra a sostener el sistema americano con todas sus fuerzas hasta consolidarse".

\footnotetext{
${ }^{5}$ De estas instrucciones diplomáticas cónocemos dos ejemplares. Uno se encuentra en ius papeles de Egaña conserva. dos en el Archivo Nacional de Santiago; el otro corre entre las copias que hizo sacar don José Toribio Medina en los archivos españoles de documentos para la historia de Chile. Esta segunda copir está muy estragada y reproduce arbitraria. mente el original. Más que la copia misma interesa la transcripción del olicio con que Osorio envió el documento a Espana. He aqui su toxto:

"El Comandante General del Ejército Real de Chile acompaña copia de Jas eredenciales e instrucciones que el gobierno insurgenie dio a su enviado extraordinario y encargado de negocios en la Corle de Londres, $\gamma$ avisa del arresto de dos individuos que las formaron. Excelentisimo Señor: Incluyo a V.E., para que se sirva ponerla en noticia de S.M., copia de las credenciales e instrucciones que se le dio por don Francisco Antonio Pérez, don José Miguel Inlante y don Agustin de Eyzaguirre, antiguos mandatarios de este Reino, al teniente coronel don Francisco Antonio Pinto, enviado extraordinario y encargado de negocios en la Corte de Londres, copiados de los libros $1^{\circ}$ y $2^{\circ}$ de correspondencia reservada por la Secretaria de relaciones exterioles, año de 1813 que existen en mi poder: a Pérez y Eyzaguirre los tengo arrestados habién. dose ya principiato sus sumarias: Infante no se halla en el Reino y según noticias está en Buenos Aires. A proporción que vaya desembarazándome de la multitud de asuntos que me rodean, consiguientes al gran desorden en que estaba $y$ he hallado este pais, iré comunicando a V.E. con el indicado objeto todas las noticias que adquiera. Dios guarde a V.E. muchos años. Santiago de Chile, 7 de noviembre de 1814 . Excmo. Señor Mfanano Osorio. Excmo. Señor Primer Secretario de Estado".
} 
Pero a renglón seguido entran las instrucciones en el viejo proyecto de Egaña de lograr la confederación de todas las provincias americanas. Cree que "el seguro medio de consolidar la América", de "hacerla respetable" y de "mantenerla tranquila" (esto es, evitar las querellas de unas provincias con otras, según resulta del contexto), es la confederación. "Es probable -agrega-que reuniéndose la América no necesite de la influencia y . uxilios de la Europa", sentencia en la cual vemos el sustentáculo de todos ius intentos posteriores de articulación de las naciones americanas hasta llegar a los de nuestros propios dias. Atisba además Egaña el germen de rivalidades que podrian ser aprovechadas por has potencias europeas para poner pie de nuevo en el continente: "es seguro - dice- que en nuestra división la potencia que auxilie a una provincia americana dividida, ha de prevalerse de su necesidad para sacar de ella todos los partidos opresivos que le proporcionen sus desgracias". Para resumir, dice finalmente:

"Todos estos principios nos invitan a una pronta confederación, y el gobierno de Buenos Aires, que es de los puntos más expuestos, deberia poner su mayor empeño en fomentarla. Creemos que acaso en Londres reunidos algunos representantes americanos pudiera agitarse y aún realizarse este objeto, y acaso las circunstancias pudieran interesar a la misma corte de Inglaterra en verificarla".

Aclara este punto en la cláusula que sigue inmẹdiatamente después:

"Su mediación (la del gobierno de .Londres, entendemos nosotros) seria la más util y eficaz, y éste era el único caso en que pudieran sacrificarse algunos privilegios para comprar tan grande bien".

No señala cuáles son esos privilegios, ni creemos nosotros que fuesen del orden político, pues no hemos encontrado en todos los papeles de Egaña, rastro alguno que nos lo muestre débil en el convencimiento de que el régimen de estas provincias debe ser necesariamente republicano. Parece, más bien, apuntar a "privilegios" comerciales, por el extraordinario desarrollo que alcanzaba en esos años el comercio británico en todos los paises del mundo, gracias a su vasta flota mercante.

El propio autor expresó algunas de estas ideas, bajo otras formas, en sus Cartas Pehuenches, vi, $18 \mathrm{ig}$ :

"La Europa y todas las naciones cultas y navegantes forman hoy una familia con tan estrechas relaciones, que una gran novedad y movimiento en alguna de ellas, altera la economia e intereses de las demás. Por consiguiente, fija todos tus cuidados en mantener relaciones permanentes con las potencias que pueden tener alguna influencia en los negocios de Chile y con las colonias insurreccionadas, para proceder de acuerdo, franquearles los auxilios que sean posibles, para hablar con los gabinetes con aquella respetabilidad que infunde el voto de muchos pueblos, y para concordar en un sistema político general, que precisamente ha de ser el término de la revolución; pues las deliberaciones de la Europa seguramente procederán en masa sobre todo el 
continente colonial, y no sobre cada pueblo en particular. Si desde el principio se hubiesen empeñado los gobiernos americanos en hablar por una sola voz convenida y acordada por todos, se avergonzarian las potencias de su miserable politica, en hacerse neutrales para la sangre y tranquilidad de medio mundo, y amigas para los negocios mercantiles. Finalmente las colonias en masa pueden proponer tratados, localidades y ventajas a que no alcanzan las proporciones de cada pueblo aislado".

Volviendo al tema de la confederación americana, que es su quimera, Egaña se pregunta en las instrucciones de $18 \mathrm{I}_{3}$ :

" ¿Deberá subsistir subrogando la Monarquia, un jefe federado que tuviese el nombre de Rey, unas relaciones que dejasen libre o pusiesen trabas en el gobierno interior y económico de las provincias y en sus relaciones comerciales, etc.?"

Por el mero planteamiento estil.stico adoptado por el autor, de su peso cae que las respuestas a estas preguntas serán para él negativas. De todos modos, por prudencia no se pronuncia:

"He aqui - dice - unas cuestiones arduisimas no sólo por su naturaleza politica sino también por la divergencia de opiniones y caprichos de los americanos; pero diremos a tiento y como en bosquejo que el nombre nos es indiferente: habiendo un consejo federativo cuyo jefe no tuviese tales atribuciones que en algún tiempo usurpasen la soberania, el poder legislativo o toda la fuerza militar, nada nos perjudicaria".

Los limites de la federación están, como se ve, expuestos con la limpidez deseable: haya federación, sean cuales fuesen sus requisitos reglamentarios, siempre que ella no usurpe la soberania de los Estados que la componen. Y en alas de su fantasia añade una proposición singular: a su juicio, éste no es un pensamiento individual suyo, ni pertenece sólo a un grupo de chilenos capaces de asumir la responsabilidad de la conducción de las relaciones exteriores; es algo más:

"Estos principios - afirma- que en la opinión del gobierno deben ser las bases y objetos a que ha de dirigirse la revolución americana, servirán a Vm. de regla para los casos particulares".

El progresivo apartamiento en que Chile recayó, años después, del ideal federativo apuntado alli, confiere importancia excepcional a las frases que hemos subrayado. ¿Creia Egaña de verdad que la revolución conducia a estas provincias a que se confederaran? ¿No se le hacia patente que, por una de las más elementales leyes biológicas, las naciones irian separándose progreșivamente antes que tender a la unión? Estas preguntas no tienen, como es de rigor, respuesta alguna que pueda salir del terreno de las hipótesis intelectuales, de modo que no nos detendremos en ellas. Las dejamos planteadas sólo para que el lector admire la profundidad de vistas de Egaña, quierı desde el apartadisimo rincón de tierra de su residencia no temia 
asomarse al panorama del mundo para ensayar sobre él juicios y pronósticos que distan mucho, por cierto, de ser baladies como alguna vez se creyó.

Siguiendo el orden cronológico de este estudio, será preciso considerar algunas observaciones contenidas en los apuntes para el Manifiesto que debe hacerse en la Declaración de la Independencia de Chile, de 1818, para entender claramente cuál era el pensamiento de Egaña en las materias que estamos discutiendo. El borrador intentado por Egaña para aquel manifiesto quedó en suspenso porque, según dijo su autor, una repentina enfermedad le habia obligado a dejarlo de mano. Desde entonces quedó guardado en los papeles originales que conserva el Archivo Nacional de Santiago, hasta que lo publicó el autor de estas lineas en los Escritos Inéditos y Dispersos de Egaña dados a luz en 1949 , p. 85 y siguientes.

La situación presentada hacia 1810 a las provincias ultramarinas del imperio español aparece bosquejada por Egaña en estos términos:

"Cuando el año de 18 Io nos avisaron a un mismo tiempo que la España ocupada y sometida a los ejércitos franceses sólo quedaba reducida al recinto de Cádiz; que los inmensos sacrificios de numerario hechos por la América para su salvación estaban disipados; que su Junta Central se habia disuelto; cuando vimos las proclamaciones de aquel gobierno previniéndonos que debiamos seguir la suerte de la metrópoli; cuando los ministros de Fernando nos amonestaban y ordenaban que debiamos someternos al Rey José; que el enviado de Estados Unidos nos instruia de todos los arbitrios secretos que se tomaban para reducir estos paises al dominio francés, entonces fue cuando circulándonos la Regencia el modelo con que se debian formar juntas arreglándose a la constituida en Cádiz, y habiendo también recibido el decreto en que el gobierno español se despedia de todas las atenciones que no se dirigiesen a la actual guerra con la Francia, establecimos nuestra Junta Gubernativa a nombre de Fernando vir y reconociendo todas las autoridades de España. Las Cortes se instruyeron de nuestras instituciones, la Regencia condescendió y ofició sobre el particular al Virrey de Lima; se imprimió nuestra acta en los papeles públicos de Cádiz, nos congratuló con grandes elogios al Embajador español en el Brasil, y la metrópoli continuó dirigiendo toda su correspondencia oficial a Chile. Seguimos el mismo plan antiguo de estrechas relaciones con Lima y ocupando todos sus buques nuestros puertos, sacaban la subsistencia para sus provincias". (Loc. cit., pp. 86-8).

Más adelante el Manifiesto estudia las dificultades que mediaban para que España hiciera un discreto uso administrativo de las provincias ultramarinas, y entonces se lee:

"Bien conocéis que un pueblo colocado a los extremos de la tierra y dividido de su metrópoli por inmensos mares y provincias que ocupan la mitad del globo, no puede ser dirigido por ella justa y oportunamente. Que 
para conseguir una dependencia servil respecto de semejante pueblo, se hace necesario el sistema adoptado hasta aqui, de aniquilar los medios de su prosperidad, representación politica, relaciones con los demás pueblos, e impedir de todos modos su población, industria y cultura. ¿Y serán conformes a la justicia y a la moral del Evangelio estos principios?" (Loc. cit., pp. $91-2)$.

Más importancia que todas estas observaciones cobran, a la luz de los acontecimientos politicos sobrevenidos después, las luminosas anticipaciones de Egaña acerca del interés que presenta para los Estados Unidos la existencia de naciones independientes con las cuales tratar, en vez de meras factorias de una metrópoli lejana. Llama a las provincias unidas de Norte América "nuestras aliadas naturales", cuando en lo juridico todavia no lo eran, y agrega que ellas "conocen muy bien que la ocupación de nuestros paises por una potencia poderosa seria siempre un manantial inagotable de precauciones y cuidados", con lo cual asoma ya el pensamiento cardinal de la doctrina llamada de Monroe. Cree, al contrario, que "la libertad de unos pueblos limitrofes formaria la época más ventajosa para aquella nación, que poseyendo la más numerosa marina mercantil ocupa las primeras aguas de sus costas y podria recibir inmediatamente sus producciones". $Y$ aun cuando la mayor parte de sus observaciones en este punto alcanzan sólo a la medida comercial, no deja de transparecer en ellas un motivo politico ulterior:

"Maestros en la industriạ y sin tener paralelos en el comercio - dice-, saben que la América libre es el canal que les señala la Providencia para llegar a la cumbre de su prosperidad, y que si los destinos les preparan el más alto imperio del comercio debe acercarse esta época cuanto se estrechen más sus relaciones con los paises agricultores de frutos preciosos y exclusivos y a quienes llama la naturaleza a una industria sedentaria" (Loc. cit., p. 96).

La luminosa sintesis del futuro que es nuestro presente, al asomar en estas lineas, basta para acreditar las dotes proféticas que residian en Egaña, Iruto tal vez de su profundo conocimiento de la historia.

Dentro del gobierno de O'Higgins, en el curso de 1818 , fue jurada la Independencia de Chile; y ya vimos que para anunciarla debió Egaña escribir un Manifiesto, que hubo de quedar inconcluso y en esbozo. Pero cuando llegó el momento de prestar el juramento, Egaña se las arregló para intercalar un voto en el cual procuraba sintetizar su doctrina politica como ciudadano de una nación independiente y soberana, y efectivamente alli se lee:

"Que siempre he entendido y me he persuadido que la suprema voluntad del pueblo de Chile al declarar su independencia y derechos, ha sido constituirse libre e independiente en cuanto a su gobierno, economias y municipalidad interior, de un modo irrevocable y permariente, fijado en una Constitución justa y liberal". 
"Que también ha querido retener en si el derecho y ejercicio de su suprema soberania en cuanto a las relaciones exteriores y representación politica entre los demás gobiernos soberanos de la tierra, pero en la calidad de anunciar y declarar a los demás gobiernos de América, en cualquier forma y dominación que existan, y a los de Europa (incluso la España), que reteniendo irrevocablemente al derecho y absoluto ejercicio de su gobierno interior, está pronto y convida y excita a los gobiernos americanos, para que se reúnan en un Congreso de Diputados, doṇde, ya sea en clase de Confederación o en una alianza perpetua y sostenida por los más indisolubles vinculos, o de cualquier otro modo mutuamente ventajoso, pueda establecerse un derecho público de América, o una soberania nacional o confederada, o cualquier otra especie de tratados que sin derogar la independencia interior y municipal, se forme un sistema general de Unión, Concordia y mutuas relaciones, en cuyo caso transmitirá Chile a la decisión de este Congreso la soberania, uso y ejercicio de todas las relaciones exteriores y derecho público nacional, conformándose con sus resoluciones en esta parte" $"$.

Esta entidad supranacional, a la cual Egaña daba en 1818 el nombre preciso de confederación, implica sostener irrevocablemente, conforme la terminologia del autor, la independencia lograda por cada una de las naciones del Nuevo Mundo, pero también significa la abdicación de la soberania en aquella fracción necesaria para lograr la unidad cabal, y sólo para ese fin y no para otros. Quien haya seguido las deliberaciones de los Estados americanos en los últimos diez años, podrá advertir cuánto de la quimera de Egaña se viene realizando en actas que cobran ya la fuerza de leyes supranacionales, y que, si no sobreviene un revolucionario cambio, con el tiempo ganarán además el peso de la tradición en favor de un entendimiento mutuo y de pactos positivos de alianza defensiva y ofensiva.

Años después, cuando se hablaba de reunir en la anfictionia de Panamá a los Estados a quienés queria confederar Bolivar, esto es en 1826, Egaña volvió a tomar la pluma para redactar el proyecto de un Acta de Confederación y mutua garantia de la independencia de los Estados que en él se menciona ${ }^{7}$. Nuevos cambios sobre la composición de este organismo supranacional pueden registrarse. Egaña piensa que, "por ahora", podrian formar parte de la Confederación los Estados Unidos, España, Portugal, Grecia, los Estados hispanoamericanos y Haiti.

Egaña dio otro toque, final tal vez, a su quimera de la confederación en el escrito titulado Instrucción en Proyecto, encargada al doctor Egaña, para proponer al Congreso convocado en Panamá las bases de uṇa federación

\footnotetext{
${ }^{6}$ El voto manifestado por Egaña en 1 प̆ 8 sc lec en los Escritus Inéditos y Dispersos, Santiago, 199, p. 100-2.

${ }^{7}$ El Acta de Confederación trabajada por Egaña para el proyectado congreso de Panamá de 1826 aparece en los Escritos Inéditos y Dispersos, Santiago, 199, p. 38-62.
} 
general entre los Estados americanos que fueron colonias españolas. Por la coyuntura señalada en ese titulo, queda en claro que esta obra fue tambièn escrita en 1826, y aparece publicada en el tomo sexto de la Colección de algunos escritos politicos, morales, poéticos y filosóficos, editado en 1836 , pucus meses después de haber fallecido su autor. El propósito general de la iniciativa puede verse en las lineas preliminares:

"Para establecer una alianza y derecho público americano, ha creido el Congreso de Chile que el medic más eficaz será formar una federación entre los Estados que fueron Colonias Españolas, a la que naturalmente los invita su uniformidad en idioma, religión, intereses, costumbres, ideas y opiniones..."

Y para dar forma a esa federación el tratadista elabora catorce articulos.

Por el primero declara el propósito de establecer "alianza y federación perpetua" entre los Estados antes señalados. Por el segundo crea el Senado federal compuesto por dos miembros representantes de cada Estado. El tercero prescribe que el Senado será soberano de la ciudad en que resida. En el cuarto señala plazo de dos años para el presidente que haya de elegir ese cuerpo. El artículo quinto dice a la letra:

"Las facultades del Senado con respecto a las relaciones exteriores de toda la federación, serán: disponer de la paz, de la guerra y de las alianzas con paises extranjeros, ya sea con toda la federación o con algún estado de ella. Los estados entre si no formarán alianzas parcialẹs. Por lo relativo al comercio, cada estado podrá establecer sus tratados particulares con los gobiernos extranjeros, siempre que no intervengan estipulaciones sobre introducción de fuerzas militares, navales o terrestres, ni bajo pretexto de seguridad, protección comercial ni otro alguno, sin la aprobación del Senado federal".

Los articulos $\mathrm{Vl}$, vil y vill disponen diversos puntos reglamentarios para el funcionamiento de aquel Senado, y el noveno dice:

"Dictadas por el congreso general las bases de la federación y del derecho común federal, el Senado formará el Código de leyes orgánicas, que en lo sucesivo podrá ampliar o corregir".

Con el titulo especial de Régimen federal interior siguen los articulos décimo hasta el final dedicados à estudiar las relaciones entre cada Estado y el Senado federal. El articulo xIv, con que termina este proyecto, está destinado a señalar el procedimiento que se debe emplear en los casos de "discordia civil" dentro de un Estado, procedimiento basado en la conciliación.

Bolivar, desprendido ya de algunas de las más urgentes ocupaciones bélicas a que hubo de entregar lo mejor de sus años, tiende la vista a las necesidades del continente americano en conjunto, y proyecta para él una especia de confederación o de alianza, a la cual en estos dias dariamos mejor el nombre de integración. El Libertador entra pues en el cuadro de las ocurrencias domésticas de Chile, del cual habia estado ausente. La invitación 
oficial extendida por el ilustre caraqueño al gobierno de Chile para designar representantes en el proyectado Congreso de Panamá, que desea realizar cuanto antes, fue comunicada al Congreso Nacional y hubo de ser considerada por éste ya en la sesión de 25 de agosto de 1826 . Este cuerpo la estudió en presencia de varios documentos (Sesiones de los Cuerpos Legislativos t. XII, p. 412-15) y acordó pedir informe a su Comisión de Relaciones Exteriores, la çual con las firmas de Elizondo, Pérez y Torres; aceptó la representación de Chile en aquella proyectada reunión (ibidem, t. xIII, p. 59-60). La resolución del Congreso Nacional demoró hasta la sesión de 16 de octubre, en la cual se aprobó un proyecto de ley de tres artículos, inmediatamente comunicado al gobierno (ibidem, t. xıl, p. 184).

Aun cuando en esta tramitación nunca se estampa el nombre de Egaña, parece evidente que éste al redactar el proyecto reseñado más arriba, tuvo en vista el que sirviera a los delegados de Chile ante el Congreso de Panamá como pauta para las consultas de los mismos, o como ponencia de éstos encaminada a dar viabilidad a la proyectada federación de los Estados americanos.

Por las fechas apuntadas puede advertirse que los delegados de Chile habrian llegado de todos modos tarde a la reunión, la cual habia suspendido sus sesiones en julio y aunque prometió reanudarlas en México, dejó en suspenso sine die sus labores. Los delegados a quienes se designó en Chile fueron José Miguel Infante y Joaquin Campino, y a ellos habria debido agregarse como secretario Santiago Muñoz Bezanilla. Las noticias relativas a la suspensión.del proyectado Congreso de Panamá llegaron a Chile en tiempo adecuado para que los representantes chilenos no emprendieran viaje. Alguna parte de la demora referida puede atribuirse al estado interno de la politica de Chile, donde a la renuncia de Freire al cargo de director supremo habian seguido mutaciones tan trascendentales como rápidas. El propio Congreso a que fue sometida la invitación habia comenzado sus tareas el 4 de julio de 1826 y funcionó con mucha asiduidad, pero sin que sus miembros supieran exactamente en qué términos estaban plánteadas sus relaciones con el poder ejecutivo. La inestabilidad politica de ese -periodo explica, pues, de sobra lo que pasó.

El tratadista que mejor ha analizado algunos de los documentos de Egaña presentados en las lineas anteriores es don Alejandro Alvarez, quien culminó su larga existencia como juez de la Corte Internacional de Justicia con asiento en La Haya. Bajo el titulo de Rasgos generales de la Historia Diplomática de Chile inició el señor Alvarez en 1911 la publicación de una obra que, según parece; debió tener varios volúmenes. De ella no conocemos sino el primero, dedicado a La Emancipación. El capitulo final de este estudio, titulado La sociedad internacional americana - Sus diferencias con la europea, se destina casi exclusivamente a considerar el proyecto de una Declaración de los derechos del pueblo de Chile, que Egaña antepuso a su 
Constitución de 1811 , editada en 1813 . Reproduce el texto en una nota, "por su importancia internacional" (p. 249), y lo comenta en términos "muy elogiosos para el autor. Después de esbozar una comparación entre Martinez de Rozas y Egaña, dice de éste:

"Egaña, por su parte, con un espiritu tal vez más tranquilo, es, sin embargo, un reformador doctrinario sumamente radical, en el sentido de que no sólo aspira a un cambio de régimen politico, sino también a una profunda transformación social.

El primero de esos documentos es una obra maestra para la época y se refiere principalmente a la situación internacional del Nuevo Mundo. Se consignan en él cuatro ideas fundamentales:

$1^{\circ}$ La independencia de los paises hispanoamericanos;

$2^{\circ}$ La unión entre todos ellos, para consolidar esa independencia y el gobierno interior de cada uno;

$3^{\circ} \mathrm{El}$ acuerdo con la Europa para llevar a la práctica estos propósitos, y

$4^{\circ} \mathrm{La}$ reunión de un Congreso General americano, para hacer respetar los derechos de las colonias emancipadas".

Alvarez no conoció, según se muestra por las citaciones hechas en su obra, sino el documento mencionado, de manera que no podemos pedirle que opine también sobre fases sucesivas del pensamiento de Egaña sobre las cuales nos hemos permitido llamar la atención en otras lineas de este breve estudio; pero su juicio, aunque parezca por eso incompleto, es digno de ser oido:

"Su proyecto es el esbozo casi profético de la politica del continente americano y contiene ya en forma precisa todos los principios que, más tarde, en 1823 , con no menos precisión y exactitud, habria de exponer el célebre Presidente Monroe de Estados Unidos, trazando desde entonces para siempre las bases de la politica internacional de los estados del Nuevo Mundo".

Y como nota a estas palabras agrega lo siguiente:

"Una observación haremos, sin embargo, a este respecto: en Egaña la solidaridad americana aparece conviniendo a los estados europeos y como resultado de su equilibrio político, al revés de Monroe, que proclama al Nuevo Mundo enteramente distinto del europeo y sin relación con ese equilibrio; pero, por otra parte, Egaña va más allá que Monroe, al proclamar la conveniencia de los Congresos internacionales americanos para crear una confederación continental".

El mismo tratadista es, por lo demás, autor de Le Droit International Americain, Paris, 1910, edit. de Pédone, obra cuyo capitulo III queda dedicado al estudio de los "caracteres generales de las relaciones internacionales de los Estados latinos de la América desde su emancipación hasta el último tercio del siglo xIx". Alli resume las sugerencias de Egaña en forma tan comprensiva como pudo verse en los párrafos anteriores, sobre todo en las páginas $41^{1-2}$ del volumen citado. 
Por el correcto análisis que hace de las instituciones propuestas por Egaña, por la oportuna comparación con el ideal de Monroe, por la claridad general del estudio, por todo, en fin, puede asegurarse que Alvarez comprendió perfectamente el proyecto de confederación sostenido por Juan Egaña, y no sólo lo expuso con simpatía y fidelidad sino que lo juzgó con verdadero acierto.

De las informaciones que se han venido leyendo queda en claro que en Chile se dió paso, en hora temprana, al concepto de la integración política de las naciones del Nuevo Mundo, como un proyecto del cual bien pudo salir, en cualquier fecha, una federación americana formada por las naciones de una misma lengua (excluidos los Estados Unidos y Brasil), o bien formada por todas ellas, sin exclusión alguna. En este segundo caso, el proyecto de Egaña, como se ha visto en la páginas anteriores, coincide bastante con la Organización de Estados Americanos en actual funcionamiento. Lo justo seria que en dicha institución, cuya sede existe en Washington, D. C., se recordara de manera positiva a Egaña, cuyo pensamiento en algún grado hizo su camino hasta desembocar en la actual OEA.

Pero de aquella relación fluye, asimismo, que la politica internacional de Chile, por lo menos en una importante fracción del siglo xix, debió inspirarse en el ideal de la integración, sea cual fuere el resultado. Conviene explicarse por qué no fue asi, y por qué, en suma, en Chile precisamente el ideal integracionista fue olvidado.

A las alturas de $182 g$ llegaba a Chile, procedente de Londres, don Andrés Bello. Había nacido en Caracas, pero salió de alli muy joven, en 1810 , y nunca más regresó. En Chile, en cambio, no sólo discurrió el resto de su vida, sino que además se sintió alentado para crear la Universidad de Chile, de la cual fue el primer Rector, para redactar el Código Civil y para llevar a cabo multitud de otras empresas, especialmente en el terreno cultural o de ilustración. Por consenso unánime, los chilenos le tienen por padre de la patria como el principal educador de toda su historia.

$\mathrm{Y}$ un duelo singular entre Bello y Egaña es el que, al parecer, sumergió el proyecto de la integración supranacional. Los dos próceres fueron en Chile muy amigos, y es fama que en la propiedad del segundo, Peñalolén, pasaron ambos muchas horas cambiando ideas y forjando proyectos para la nación a la cual los dos servian en la medida de sus fuerzas. De la estimación que se profesaron no cabe duda alguna; pero en medio de aquella comunicación de espiritus hubo una diferencia muy señalada en torno al ideal de la integración. A Bello se le presentó la oportunidad de darle forma pública cuando. en 1850, hubo de dar cuenta a sus lectores de la Revista de Santiago de una Memoria histórico-crilica del Derecho Público Chileno, obra compilada por Ramón Briseño. Alli encontró referido el proyecto de Egaña; y sobre él se pronunció en los siguientes términos:

"Esta fue la primera idea de un congreso general americano; pues aun- 
que son invitadas a él todas las provincias españolas, se trasluce en el proyecto mismo la improbabilidad de obtener su universal concurrencia, y es de creer que sólo se consideraba realizable la incorporación de los pueblos españoles del continente sudamericano bajo un gobierno federativo, como el de los Estados Unidos de América. Pero, aun circunscrita a estos limites, ¿no era ésta una concepción más brillante que sọ́lida? Prescindiendo de las circunstancias en que se hallaban los pueblos sudamericanos en 1811 y después y que hacian enteramente impracticable hasta el paso preliminar de la invitación, ¿ habria sido posible dar una apariencia siquiera de unión a sociedades diseminadas, como los oasis de un desierto, sobre un espacio inmenso, con pocos puntos de contacto eńtre si, sin medios expeditos de comunicación, ocupadas en un objeto que lo resumia todo: la resistencia a las tercas pretensiones de la metrópoli, la guerra? El señor Briseño cree ver consumado en todas partes el programa del proyecto; pero en nuestra humilde opinión, ha sido todo lo contrario. El proyecto aspiraba a nada menos que a la erección de un gobierno federal que, dejando a cada uno de los asociados su administración interior, los atase a todos, reglase sus intereses comunes y tomase su voz para con el resto del mundo. $i$ Y qué es lo que hoy existe de hecho y de derecho en las repúblicas hispano americanas? Naciones varias, idénticas sin duda en origen, religión, lengua y costumbres, y que, con todo eso, no tienen lazos más estrechos entre si-que los estados de la peninsula italiana antes de la revolución francesa; que Nápoles, Roma, Toscana, Módena y Cerdeña en el dia. Cada una de ellas dirige a su arbitrio, no sólo sus negocios interiores, sino sus relaciones externas. $Y$ ya se ven brotar en ellas intereses peculiares y opuestos, aspiraciones y controversias que probablemente no hallarán una solución final sino en el campo de batalla. Pero qué! $i$ No hizo Colombia la guerra al Perú? $\dot{c}$ Buenos Aires al Paraguay? ¿El Perú a Bolivia? ¿Chile a la Confederación Perú-boliviana? ¿No hierve todavia la larga querella de la federación argentina con la República Oriental? La completa separación de las repúblicas hispanoamericanas es el hecho indisputablemente consumado".

Bello hizo más todavia: vinculó el proyecto de Egaña a los de Bolivar, concediendo la prioridad al primero, cual puede verse en las siguientes palabras:

"Aquella alma ardiente de Bolivar, para quien lo grandioso, lo colosal, tenia un prestigio irresistible, quiso en vano resucitar la idea de don Juan Egaña. El congreso de Panamá, uno de sus pensamientos de predilección, abortó. La república misma de.Colombia, su obra peculiar, fue una creación efimera; al cabo de pocos años de una existencia débil y achacosa, sus principios interiores de repulsión prevalecieron; los tres vastos cuerpos unidos en ella se desprendieron espontáneamente; y sin convulsión, sin estrépito, volvieron al estado natural de disociación, que las glorias militares 
de Acción para la Integración de América Latina y finalmente, y en una escala mucho más modesta, la contribución que la Escuela Latinoamericana de Ciencia Poltica y Administración Pública de Flacso, viene haciendo al proceso de integración mediante la preparación del primer anteproyecto concreto sobre constitución de la Comunidad Económica Latinoamericana, presentado al Parlamento Latinoamericano; todos estos y muchos otros más, son indicadores del volumen y de la intensidad que va adquiriendo el proceso de integración en América Latina.

Se ha dicho que para muchos paises de América Latina, la integración es todavia una quimera ${ }^{20}$. Usando el lenguaje de los estudios prospectivos, podemos decir que la integración de América Latina es una utopia accesible ${ }^{21}$. Su realización, con profundo sentido latinoamericano, dependerá de la vocación, del coraje y de la capacidad politica de esta generación latinoamericana.

\footnotetext{
${ }^{20}$ Stanley Hoftman, Obstinate or Obsolete? The Fate of the Nation State and the Case of Western Europe. Daedalus, 95, $\mathrm{N}^{\mathrm{N}}$ 3. Summer 1900.

${ }^{21}$ Ver Etapes de ta Prospective. Bibliotheque de Prospective. Presses Universitaires de France. 1907 , p. $34^{0}$.
} 